\title{
Mathematical Methods for Identification of Core Competitors: Based on Social Networks and Hierarchical Cluster Analysis
}

\author{
Ming Wen, ${ }^{1}$ Mingxing Li, ${ }^{2}$ Cheng Hu, ${ }^{2}$ Saifullah Hakro, ${ }^{3}$ Abid Hussain $\left(D,{ }^{2,4}\right.$ \\ Mohammad Heydari $\oplus^{5}{ }^{5}$ Kashif Imran Zadi, ${ }^{4}$ and Shumaila Arzo ${ }^{6}$ \\ ${ }^{1}$ Jiangsu Intellectual Property Research Center, Jiangsu University, Zhenjiang 212013, China \\ ${ }^{2}$ School of Management, Jiangsu University, Zhenjiang 212013, China \\ ${ }^{3}$ Department of Management Sciences, University of Okara, Okara, Punjab, Pakistan \\ ${ }^{4}$ University of Management and Technology, Johar Town, Lahore 54782, Pakistan \\ ${ }^{5}$ Business College, Southwest University, Chongqing 400715, China \\ ${ }^{6}$ School of Public Affairs, Zijingang Campus, Zhejiang University, Hangzhou 310058, China \\ Correspondence should be addressed to Abid Hussain; abidhusssain02@gmail.com
}

Received 21 September 2021; Accepted 23 October 2021; Published 9 November 2021

Academic Editor: Gianpaolo Di Bona

Copyright (C) 2021 Ming Wen et al. This is an open access article distributed under the Creative Commons Attribution License, which permits unrestricted use, distribution, and reproduction in any medium, provided the original work is properly cited.

Based on the introduction of complex social network theory and methods, this study reveals enterprises' patent layouts to help Chinese enterprises distinguish the core competitors. This study uses the social network analysis method and the system cluster analysis method to systematically analyze the macro technology development trend and competitors' micro technology innovation points. Based on the structure of enterprise resource investment, a two-dimensional matrix with the keyword "similarity-technological competition intensity" was constructed to accurately identify BYD's core technological competitors. In China, BYD company should regard GX company and ND company as core technology competitors, pay attention to the technology development direction and patent layout of YW company and HD company, and pay attention to the patent dynamics of GLM company and YQ company in specific technological innovation points.

\section{Introduction}

In recent years, China has been vigorously developing new energy, materials, and technology-based strategic emerging industries. As one of the new energy industries, the lithium battery industry also steps into the fast development track. Affected by the growth of the new energy vehicle market and national policies, domestic demand for lithium-ion production equipment exceeded 17 billion yuan in 2017. China has become the world's leading production base for lithiumion power batteries for vehicles. As the lithium battery industry enters a rapid growth period, the number of enterprises in related fields is rapidly rising. The competition between enterprises in the industry is becoming increasingly fierce; quickly and efficiently identifying the core competitors has become the key to gaining a competitive advantage in the market. Based on literature analysis, there are different kinds of methods for identifying core competitors of enterprises.

The first method is called patent information analysis. The profitable market and technical information can be obtained from background technology and invention content in patent specifications. Many scholars currently choose to identify their core competitors with the help of mining and analyzing patent literature. This is because patents reflect the technical value and market information of competitors. Based on LDA semantic analysis technology, Shi et al. [1] put forward a potential competitor identification process including four steps: collecting and preprocessing patent data, building a corpus, preliminarily identifying potential competitors, and discriminating potential competitors.

The second method is called the competitive isomorphism method. Competitive isomorphism refers to the 
phenomenon that competitive enterprises become similar and imitate each other under joint market forces. According to Gautam et al. [2], a new competitor identification prediction model is proposed to evaluate the presence of online isomorphism and its role in predicting competitors through online metrics. The third method is called the PTCM method. PTCM includes steps such as patent collection, patent index calculation, and change detection. Meng-Jung et al. [3] used PTCM methodology in Taiwan's semiconductor industry to help managers develop appropriate business strategies through competitive intelligence analysis.

The fourth method is called the probability similarity method. According to research results done by Ji et al. [4], as one of the measuring methods, probability similarity was used together with a clustering algorithm to conduct the automation of competitor identification process based on big data of social media and geographic distance. The fifth method is called the multidimensional scaling analysis with an interfirm technological similarity matrix. The degree of similarity between firms is represented by the distance between the points in the space. The closer the position of the firm is to the center of the similarity matrix, the more central it is. According to this method held by Song et al. [5], the similarity matrix between companies and multidimensional scaling analysis are used to identify competitors in the semiconductor industry.

The sixth method is called the two-stage model. It is composed of competitor identification and competitor analysis. Bergen and Margaret [6] used the two-stage model to explain the analysis framework of different kinds of competitors. The seventh method is called the patent similarity method. The higher the degree of patent similarity, the higher the intensity of technological competition between enterprises, which means that the enterprises are confronted with the technological competition between them. Martin [7] used the cosine coefficient, Jaccard coefficient, and Sorensen index to identify technical competitors from the angle of enterprises.

Based on the above considerations, competitive relationships between firms can be divided into technological and nontechnological competition. Nontechnical competitive relationships such as product competition and market competition must depend on competitive technical relationships. Technological similarity can only arise between firms in a competitive technological relationship, which can eventually be mapped to products to produce product similarity, giving rise to product and market competitive relationships. Therefore, of all the competitive relationships of a firm, technological competition is the most fundamental. Identifying the firm's technical competitors is the most critical part of identifying all types of competitors. In the framework of enterprises' core competitiveness, innovation capacity, including technological innovation, research, development capabilities, and patented technology, is the backbone of enterprises' core competitiveness.

Although the existing enterprise technology competitor identification research has analyzed the enterprise competitor intelligence from multiple angles, such as patent quantity, patent technical characteristics, and patent litigation situation, each research angle is relatively independent of the others, thus making the enterprise core competitor positioning vague and unable to meet the enterprise's precise and efficient positioning needs. Accordingly, this paper takes patent technology features as a research perspective. It takes BYD as an example to systematically analyze its competitors' macro technology development direction and micro technology innovation points from both macro and micro perspectives [8]. Simultaneously, the empirical research on identifying the core competitors of lithium battery enterprises is carried out in light of the enterprise's resource investment structure. This basis provides relevant countermeasures and suggestions for the patent layout and patent competition strategy formulation of enterprises, which has specific theoretical and practical significance [9]. These groups of technology particularly and many other innovations will generate, in the opinion of the consultants, the greatest influence on the business landscape and development of the industry all over the world. As evidenced by scientific research on the development of technology trends in different countries, such macro technological forces remain the basis for innovations and business transformation [10]. It is important, in our opinion, to compare innovative technological trends followed by leading companies during recent decades. The global technological trends contribute to the expansion of innovations and the strengthening of competition; therefore, the ability of an organization to use technology to its advantage will determine its effectiveness in the future. Modern technologies define the strategic context and become an apparent priority of many businesses [11]. The main novelty or contribution of this work is the identification of the research lines that have been developed so far, based on the grouping of keywords through the analysis of cooccurrences, to build a map of the work carried out by the driving agents of the theme and, furthermore, based on the above different methodologies of literature developed by the scholars Ludo Waltman and Nees Jan van Eck, from the Center for Science and Technology Studies (Leiden University, Netherlands), the ten most relevant emerging lines of research on the link between the $\mathrm{BC}$ technology and the secure accounting management, to open new avenues to develop.

\section{Materials and Methods}

2.1. The Social Network Visualization Model. This paper uses a social network visualization model to measure the sample firms' technological competition to construct a coupled network of IPC numbers among the sample firms and measure their relative point centrality $[12,13]$.

The formula for the relative point centrality is $C(i)=d\left(N_{i}\right) / n-1$, where $C(i)$ represents the relative point degree centrality of node $n i, n$ is the total number of nodes, and $d(n i)$ represents the absolute point degree centrality of node $n i$. The formula is $d\left(N_{i}\right)=\sum_{j} X_{i j}, X_{i j}=0$ (when node $n i$ is not directly adjacent to $\mathrm{N}_{j}$ ), $X_{i j}=1$ (when node $n i$ is directly adjacent to $\mathrm{N}_{j}$ ). In an IPC-coupled network, the larger the firm's nodes, the higher the relative point degree 
centrality, indicating that the firm has a broader range of technological competitions with other firms.

2.2. The Technological Competitive Intensity Model. The intensity of technological competition between firms depends not only on the scope of technological competition but also on how the two firms devote resources to the relevant technological transformation. The scale of resource investment can determine the final product size and market share, thus influencing firms' competition. Since it is difficult to analyze the application of competitors' patented technologies and their preferences for resource investment, this paper assumes, based on the theory of rational economic man, that all the patented technologies applied for by a firm are applied in actual production to maximize the value of the firm [14]. Besides, if an enterprise adopts an equal distribution of patent technology resources, the more significant the number of patents in a field, the more significant the proportion of resources invested by the enterprise in that field, and the greater the consistency of the enterprise's attention to technological innovation in the relevant area with the actual situation.

Based on the above assumptions, the number of patients with duplicate IPC numbers with competitors accounts for the proportion of the total number of active patents, measuring the degree of emphasis on resource investment in competing technologies [15].

The competitive intensity of IPC technology is $P_{i j}=A_{i j} / A_{i} \times A_{i j} / A_{j}$ (where $A_{i j}$ denotes the number of effective patents in the same technology field of firm $i$ and firm $j, A i$ denotes the number of all effective patents of the firm $i$, $A_{j}$ denotes the number of all effective patents of firm $j$, and $P_{i j}$ indicates the intensity of the IPC competition between firm $i$ and firm $j$; the larger the value of $P_{i j}$, the more intense the technology competition between the two firms based on the IPC analysis). The rationale of this algorithm is that $\overline{\mathrm{Ajai}}$ and $A_{i j} / A_{j}$ can measure the resource investment of firm $i$ and firm $j$ in competing technologies. If $A_{i j} / A_{i}$ and $A_{i j} / A_{j}$ are more extensive, both firm $i$ and firm $j$ invest more resources and attach more importance to the crossover technology area. The competition between the two firms will be in the crossover technology area, and the final quantitative result is an increase in the $P_{i j}$ value. Therefore, the $P_{i j}$ value can effectively measure the intensity of the IPC competition between the two firms.

2.3. Keyword Similarity Measurement Model. IPC number represents the enterprise's technology development direction, and the analysis of competitors' IPC number helps determine the technology development trend and patent layout of competitors. However, the same IPC number usually contains more technical innovation points, and a patent of an enterprise is often the technological innovation surrounding a certain innovation point. To explore the similar innovation points between the sample enterprises, this paper uses the angle cosine to measure the similarity of keywords between the sample enterprises and standardizes the raw data through the clustering method to eliminate the shortcomings of the traditional European distance clustering method, which is greatly influenced by the unit order of magnitude. Since the standardized variables have a mathematical expectation of 0 and a variance of 1 , the standardized variables for $X$ can be expressed as follows when the sample set $X$ is derived with a mean of $M$ and a standard deviation of S: $X^{*}=X-M / S$. Two $n$-dimensional vectors can be derived from $\rightarrow \overrightarrow{X i, X}_{j}$. Then, the cosine of the angle between two $n$-dimensional samples can be defined as $\cos X_{i j}=\overrightarrow{X_{i}} \cdot \overrightarrow{X_{j}} /\left|\overrightarrow{X_{j}}\right| *\left|\overrightarrow{X_{i}}\right|$.

The range of values for the angle cosine is $[-1,1]$. A higher value indicates that the smaller the angle between the two vectors, the higher the keyword similarity between the samples and the lower the opposite.

2.4. Data Sources. A core technology competitor is a competitor having direct technological competition and posing the most severe technological threat. To help lithium battery companies accurately and efficiently identify their core technology competitors, this paper conducts an empirical study using BYD as an example. It selects the top ten companies in the " 2016 China Lithium Battery Enterprises Comprehensive Strength Ranking" list published by Xinhua as a sample of competitors to analyze the technical characteristics of BYD and its competitors. After eliminating the companies that have no technological crossover with other lithium-ion battery companies, the leading research companies in this paper are GX, TN, DS, WL, TQ, HD, ND, GF, YW, and GLM. To enhance the purity of academic research, all company names in this paper are replaced by enterprise codes.

The reasonableness of this sample selection is as follows: The "2016 China Lithium Battery Enterprise Comprehensive Strength Ranking" list assesses China's lithium battery enterprises from four aspects, namely, enterprise scale, business performance and asset operation, corporate governance, and social responsibility. This assessment index shows that the top ten competitors pose a more profound overall threat to BYD in terms of technology competition, market scale competition, and business performance competition than other enterprises. Only the transformation of innovative technologies into results and then into practical production applications can generate economic value, thus helping enterprises gain competitive advantages. Therefore, an enterprise's competitive advantage depends not only on the quantity and quality of its innovative achievements, but also on the extent to which it invests resources in applying and transforming technology and its economic strength.

The ten competitors selected in this paper are similar in financial stability to BYD, which virtually eliminates the impact of economic strength disparity on its technology competitive analysis. Based on the above considerations, this article provides an in-depth analysis of the macro technology trends and micro technology innovation points of ten of BYD's competitors. It identifies those companies with which BYD is competing in core technologies, thus providing BYD with feasible suggestions for its patent competition strategy. The relevant patent data in this paper were obtained from the 
State Intellectual Property Office of the People's Republic of China (accessed at http://www.sipo.gov.cn/) and the Baiten Patent Database (accessed at http://so.baiten.cn/).

\section{Results and Discussion}

3.1. Analysis of the Scope of Technological Competition in the Industry. The International Patent Classification (IPC) promulgated by the World Intellectual Property Organization (WIPO) is a standard international classification method for patent technology. The IPC number represents the coverage of patent technology and the direction of technology development of enterprises [16]. The greater the number of repetitions of IPC numbers between different firms, the greater the technological competition between them, indicating more technically identical or similar areas. This paper classifies and organizes the sample enterprises' IPC numbers and counts the standard IPCs among different enterprises (Figure 1). Figure 1 shows that the common IPC numbers among the sample enterprises are mainly concentrated in the three categories of H01M2, H01M4, and H01M10.

This paper draws the coupling network of IPC numbers of the sample firms with UCINET software to further analyze the lithium battery industry's competitive technological situation. It measures the point degree centrality of the sample firms (Table 1). From Table 1, it can be seen that BYD's relative point centrality is 50.357 , which is much higher than that of other competitors, indicating that BYD has the most significant power influence in the IPC number crossover network and has the most considerable number of coupled IPC numbers with other competitors, that is, the broadest area in which BYD company has technology competition with other rivals. BYD company needs to be alert that an overall technology sector is beneficial to its market expansion.

Still, at the same time, companies are subject to increased technology competition and patent infringement lawsuits. As can be seen in Figure 2, the IPC numbers that BYD has coupled with other competitors are also focused on the three categories H01M2, H01M4, and H01M10. H01M2 is a structural part or manufacturing method of an inactive part, H01M4 is an electrode, and H01M10 is a secondary battery and its manufacturing. Combined with the development trend of lithium battery technology, we can see that the structure of inactive parts or manufacturing methods and electrodes are the primary technical fields of lithium battery production and manufacturing.

In contrast, the secondary battery is at the forefront of the lithium battery industry and the hot technical areas. This demonstrates BYD's ability to keep up with its technology development by focusing on fundamental lithium battery technology and the industry's forwardlooking technology areas. On the other hand, since both fundamental and frontier technologies are crucial to lithium-ion battery enterprises, technical competition in related fields will intensify in the future. BYD company should continue to increase its $R \& D$ and technology

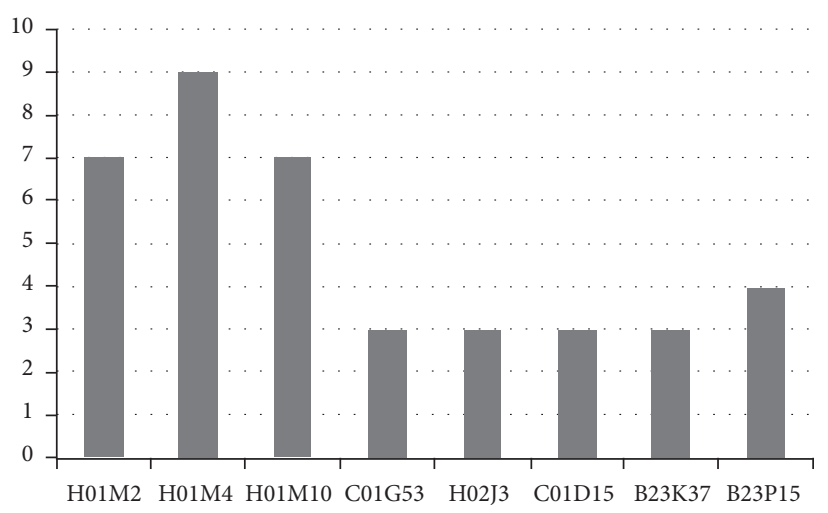

FIgURE 1: Shared IPC number distribution in lithium battery enterprises.

TABLE 1: Centrality of sample enterprises.

\begin{tabular}{lccc}
\hline Company name & Centrality & Company name & Centrality \\
\hline BYD & 50.357 & YW & 11.786 \\
GX & 22.143 & GF & 7.857 \\
HD & 16.786 & TQ & 7.500 \\
WL & 13.571 & DS & 1.786 \\
GLM & 13.214 & TN & 1.429 \\
ND & 12.143 & & \\
\hline
\end{tabular}

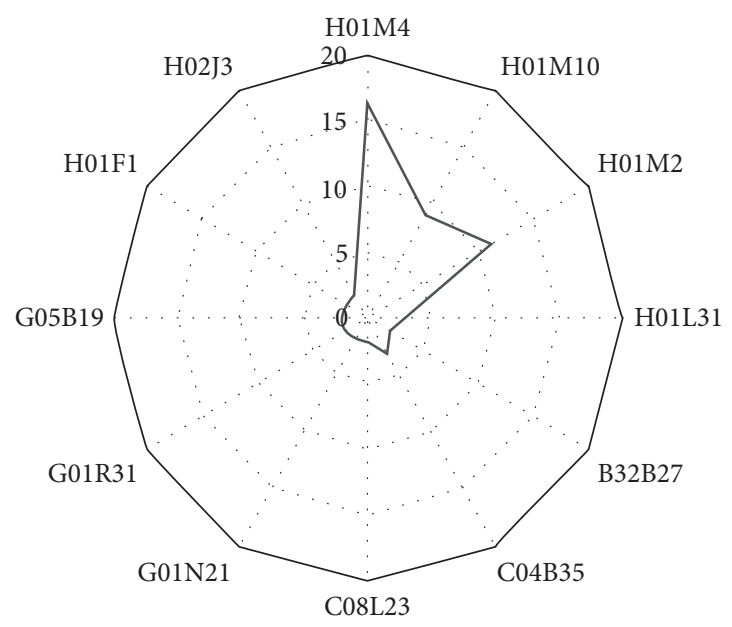

FIgURE 2: Coupled IPC distribution of BYD company and competitors.

transfer in associated areas to gain a competitive advantage in essential and popular technologies.

3.2. Competitive Intensity Analysis of IPC Technologies. The analysis of the competitive intensity of IPC technology between BYD and its competitors (Table 2) shows that GX and ND have the highest competitive passion for IPC technology with BYD (their values are, respectively, 0.0644 and 0.0282). Table 3 shows that GX and ND's patented technology covers lithium batteries' core technology (H01M4 electrode and H01M10 secondary battery) and 
TABLE 2: Competitors' IPC technology competitive strength.

\begin{tabular}{lcc}
\hline Ranking & Competitors & IPC technology competitive strength \\
\hline 1 & GX & 0.0644 \\
2 & ND & 0.0282 \\
3 & YW & 0.0234 \\
4 & HD & 0.0233 \\
5 & GLM & 0.0113 \\
6 & WL & 0.0111 \\
7 & TQ & 0.0108 \\
8 & DS & 0.0066 \\
9 & GF & 0.0050 \\
10 & TN & 0.0006 \\
\hline
\end{tabular}

TABLE 3: IPC distribution of GX and ND.

\begin{tabular}{|c|c|c|c|c|c|c|}
\hline Company name & IPC numbers & Number of patents & IPC numbers & Number of patents & IPC numbers & Number of patents \\
\hline \multirow{8}{*}{ GX } & H01M4 & 17 & B65H18 & 1 & G01N25 & 1 \\
\hline & H01M10 & 6 & C01G31 & 1 & G01N3 & 1 \\
\hline & G01R31 & 2 & C07C55 & 1 & G01N30 & 1 \\
\hline & B23K37 & 1 & G01B7 & 1 & G01N31 & 1 \\
\hline & $\mathrm{B} 23 \mathrm{~K} 11$ & 1 & G01M3 & 1 & G01N5 & 1 \\
\hline & B23B9 & 1 & G01N15 & 1 & G08C17 & 1 \\
\hline & B60L11 & 1 & G01N21 & 1 & H01M2 & 1 \\
\hline & $\mathrm{H} 01 \mathrm{M} 4$ & 13 & $\mathrm{C} 01 \mathrm{~B} 25$ & 2 & $\mathrm{H} 02 \mathrm{~J} 3$ & 1 \\
\hline \multirow[t]{2}{*}{ ND } & H01M10 & 5 & C08L55 & 1 & & \\
\hline & H01M2 & 2 & $\mathrm{C} 23 \mathrm{C} 20$ & 1 & & \\
\hline
\end{tabular}

auxiliary technology for lithium battery manufacturing (C01G31 chemical material and G08C17 circuit device). In the future, BYD should keep an eye on the patent technology development direction of GX and ND, especially the common trend between core technology and auxiliary technology, to be alert to competitors' patent layout of Li-ion battery technology. Simultaneously, BYD company should also be aware of its competitors' resource investments in cross-cutting technology areas to anticipate the next steps in their R\&D and patent strategies based on the changing resource structure and gain a competitive advantage in the marketplace.

Finally, BYD company should adjust its resource allocation structure based on the direction of its competitors' technology development and market demand and invest more resources in technology areas where market demand is high. It is vital to be able to compete with its competitors in hot technology areas. The intensity of IPC technology competition is positively correlated with the resource allocation structure of competing parties. BYD company should not only pay attention to its competitors' patents, but also consider competitors' patent technology distribution and resource allocation and adjust its patent strategy and resource allocation structure based on competitors' different technology intensity and market development needs. Suppose the patented technology with high intensity belongs to the noncritical technology field [17].

In that case, the enterprise can appropriately reduce the proportion of resources invested in the relevant area or even withdraw from the pertinent field to avoid patent infringement disputes. Suppose that the patent technology with high intensity belongs to the required technology field. In that case, the enterprise should continue increasing the proportion of $\mathrm{R} \& \mathrm{D}$ investment to improve the patent quality in the relevant area and occupy the high point of competitive market advantage. BYD should also pay attention to the distribution of competitors' IPC numbers and the IPC competition's strength to identify its core technology competitors and analyze the core competitors' technology development direction. Patent layout based on IPC distribution numbers informs its patent strategy [18].

3.3. Industry Technology Innovation Point Analysis. To further explore the technological innovation features of the competitors, this paper, through the research method of literature search and analysis, uses the BICOMB software to compare and analyze the patent names and patent claims of the sample enterprises, screens out 22 feature keywords, and constructs the feature keyword distribution percentage matrix of the sample enterprises on this basis (Table 4). To eliminate the influence of quantitative differences between different enterprises on the clustering results, this paper standardizes the data in Table 4. It then performs SPSS cluster analysis on the standardized data (Figure 3 ). Figure 3 shows that BYD is first clustered with GX in terms of individual clustering, which is consistent with the IPC technology competitive intensity results, indicating that GX has a broader range of technology crossover with BYD's more similar micro technology innovation points.

From Table 4, we can see that BYD's core technology innovation points in the lithium battery industry all have 
TABLE 4: Distribution percentage of characteristic keywords.

\begin{tabular}{|c|c|c|c|c|c|c|c|c|c|c|c|}
\hline \multirow{2}{*}{ Keywords } & \multicolumn{11}{|c|}{ Company } \\
\hline & BYD & $\mathrm{HD}$ & GX & ND & WL & YW & GLM & GF & DS & TQ & $\mathrm{TN}$ \\
\hline Battery casing & 0.55 & 0.00 & 3.67 & 0.00 & 0.00 & 0.00 & 0.00 & 0.00 & 0.00 & 0.00 & 0.00 \\
\hline Power batteries & 4.98 & 0.00 & 1.83 & 0.00 & 0.00 & 0.00 & 0.00 & 0.00 & 0.00 & 0.00 & 0.00 \\
\hline $\mathrm{Li}_{2} \mathrm{FePO}_{4}$ & 4.98 & 0.00 & 2.75 & 0.00 & 0.00 & 0.00 & 0.00 & 0.00 & 0.00 & 57.14 & 0.00 \\
\hline $\mathrm{LiFePO}_{4}$ & 0.92 & 10.61 & 13.76 & 30.77 & 50.00 & 5.26 & 0.00 & 33.33 & 0.00 & 0.00 & 0.00 \\
\hline Battery heating methods & 8.67 & 0.00 & 0.00 & 0.00 & 0.00 & 0.00 & 0.00 & 0.00 & 0.00 & 0.00 & 0.00 \\
\hline Anode materials & 14.94 & 7.58 & 29.36 & 30.77 & 0.00 & 15.79 & 66.67 & 33.34 & 0.00 & 28.57 & 0.00 \\
\hline Cathode materials & 11.99 & 0.00 & 11.93 & 23.08 & 0.00 & 5.26 & 0.00 & 0.00 & 0.00 & 0.00 & 0.00 \\
\hline Secondary battery & 23.25 & 0.00 & 1.83 & 0.00 & 0.00 & 0.00 & 0.00 & 0.00 & 0.00 & 7.14 & 0.00 \\
\hline Polaroid & 2.40 & 3.03 & 2.75 & 7.69 & 0.00 & 5.26 & 0.00 & 0.00 & 0.00 & 7.15 & 0.00 \\
\hline Polaris & 0.37 & 0.00 & 0.92 & 0.00 & 0.00 & 5.26 & 0.00 & 0.00 & 0.00 & 0.00 & 0.00 \\
\hline Diaphragms & 3.87 & 0.00 & 4.59 & 7.69 & 0.00 & 10.53 & 33.33 & 0.00 & 0.00 & 0.00 & 0.00 \\
\hline Paste & 2.40 & 0.00 & 1.83 & 0.00 & 0.00 & 0.00 & 0.00 & 0.00 & 0.00 & 0.00 & 0.00 \\
\hline Electric cores & 1.11 & 0.00 & 0.92 & 0.00 & 0.00 & 10.53 & 0.00 & 0.00 & 0.00 & 0.00 & 0.00 \\
\hline Sealing components & 2.21 & 0.00 & 0.00 & 0.00 & 0.00 & 5.26 & 0.00 & 0.00 & 50.00 & 0.00 & 100.00 \\
\hline Ferrous oxalate & 0.74 & 0.00 & 0.92 & 0.00 & 0.00 & 0.00 & 0.00 & 33.33 & 0.00 & 0.00 & 0.00 \\
\hline Battery pack & 5.54 & 0.00 & 4.59 & 0.00 & 50.00 & 10.53 & 0.00 & 0.00 & 0.00 & 0.00 & 0.00 \\
\hline Winding devices & 0.74 & 0.00 & 4.59 & 0.00 & 0.00 & 15.79 & 0.00 & 0.00 & 0.00 & 0.00 & 0.00 \\
\hline Lithium titanate & 0.37 & 0.00 & 9.17 & 0.00 & 0.00 & 5.26 & 0.00 & 0.00 & 0.00 & 0.00 & 0.00 \\
\hline Charging and discharging equipment & 6.27 & 0.00 & 4.59 & 0.00 & 0.00 & 0.00 & 0.00 & 0.00 & 0.00 & 0.00 & 0.00 \\
\hline Magnet materials & 2.03 & 78.78 & 0.00 & 0.00 & 0.00 & 0.00 & 0.00 & 0.00 & 0.00 & 0.00 & 0.00 \\
\hline Electrode terminals & 0.92 & 0.00 & 0.00 & 0.00 & 0.00 & 5.25 & 0.00 & 0.00 & 25.00 & 0.00 & 0.00 \\
\hline Power detection devices & 0.75 & 0.00 & 0.00 & 0.00 & 0.00 & 0.00 & 0.00 & 0.00 & 25.00 & 0.00 & 0.00 \\
\hline
\end{tabular}

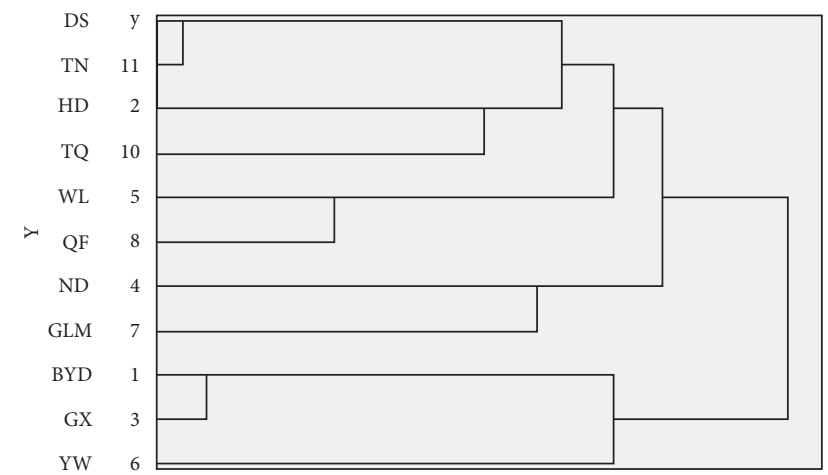

Figure 3: Cluster analysis diagram of standardization processing.

valid patents, which on the one hand indicates that BYD has a wide range of business and pays more attention to technology innovation in each branch of technology. On the other hand, it also demonstrates that BYD's patent technology points cover the entire lithium battery production chain with high technical integrity. Combining this with the distribution of keywords, we can see that a large number of enterprises have valuable patents in lithium iron phosphate materials, anode materials, cathode materials, electrode plates, separator devices, sealed components, battery packs, and other technological innovation points, indicating that the above technological innovation points are the fundamental and frontier technology innovation points in the lithium battery industry [19]. As the basic technology and frontier technology innovation point is the "battlefield" of the lithium battery enterprises, with the gradual increase in the number of patent applications of the lithium battery enterprises in the relevant technological innovation point, the patent infringement disputes between the enterprises will also increase more and more. Going forward, BYD company should establish an early warning mechanism to identify potential patent infringement dispute risks in both primary and popular technology areas. Besides, fundamental technology is the foundation for other lithium battery extensions. BYD company should focus on technological innovation in essential areas, which will provide a substantial competitive advantage for future business expansion and enterprise transformation and upgrading.

3.4. Core Technology Competitor Identification. In this paper, we take the similarity of feature keywords as the vertical coordinate and the competitive strength of IPC technology as the horizontal coordinate, draw a two-dimensional scatter diagram of sample enterprises (Figure 4), add a reference line based on the difference in the spread of sample enterprises, and construct a two-dimensional matrix for the identification of core technology competitors. From Figure 4, BYD company's technology competitors can be divided into four categories. Among them, GLM and TQ companies constitute one of the categories characterized by high similarity of keywords. Still, with low competitive intensity of IPC technology, BYD company should be more vigilant for patent infringement disputes with GLM company and TQ company at a particular technology innovation point. YW and HD firms are characterized by the high competitive intensity of IPC technology but the low similarity of feature keywords. In the future, BYD company should pay more attention to YW and HD's technology trends and the correlation between the different technology 


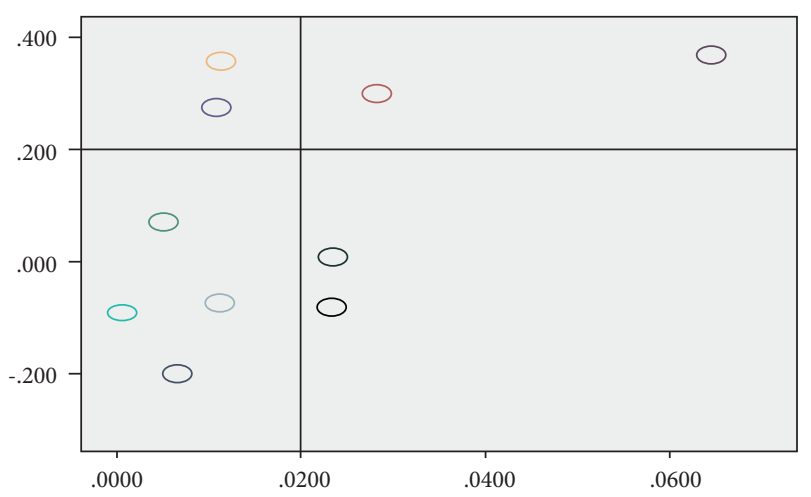

Figure 4: Two-dimensional matrix of technical competitor identification.

TABLE 5: Keyword similarity between BYD and competitors.

\begin{tabular}{lcc}
\hline Company & Angle cosine & Feature keyword similarity ranking \\
\hline GX & 0.370 & 1 \\
GLM & 0.358 & 2 \\
ND & 0.299 & 3 \\
TQ & 0.275 & 4 \\
GF & 0.070 & 5 \\
YW & 0.008 & 6 \\
WL & -0.074 & 7 \\
HD & -0.081 & 8 \\
TN & -0.091 & 9 \\
DS & -0.201 & 10 \\
\hline
\end{tabular}

directions to promptly detect YW and HD's patent layout. DS, TN, WL, and GF are firms characterized by the low, competitive intensity of IPC technology and similarity of feature keywords (Table 5).

As a result, the technological threat posed by these four companies to BYD is relatively small, and BYD can pay less attention to the patent developments of these four companies and instead divert its resources to conducting patent intelligence analysis on other more threatening competitors [20]. However, it should be noted that some of the competitors in these four companies also pose a more significant technological threat to BYD due to their strategic positioning and other reasons, as they invest a much higher proportion of their resources in individual technology innovation points than other competitors. For example, TN has invested $100 \%$ of its resources in sealing components (Table 4) and has significant technological competitive advantages. Therefore, BYD company should also pay due attention to the patent dynamics and market share changes of such competitors in specific technology innovation points to prevent them from creating monopolies around a particular innovation point.

The last category of competitors includes GX and ND, characterized by more remarkable similarities with BYD company in terms of technology distribution characteristics and the number of similar patented technology innovation points. Therefore, BYD should list GX and ND as core technology competitors. Analyzing the elements of BYD, ND, and GX, we see that BYD has invested 14.94\%, 11.99\%,
$2.40 \%$, and $3.87 \%$ of its resources in the four technology innovation points of cathode material, anode material, electrode sheet, and diaphragm device, respectively. The proportion of ND and GX in these four technology innovation points is comparable to that of BYD, so these three companies will compete fiercely in the related fields. Combined with Li-ion battery products' structural characteristics, the cathode material, anode material, electrode sheet, and separator are all indispensable components in Liion batteries' production. Therefore, BYD should continue to increase its $R \& D$ expenditure and $R \& D$ personnel in these areas to increase the number and quality of patents in these areas, actively counteract the technological threats from competitors, and strive to gain a competitive advantage in these key lithium battery technology areas. Besides, BYD company should watch competitors' patents in related fields to prevent duplication of research and development and patent circumvention. Simultaneously, BYD company should also deploy patents in related fields and create its own "patent ecosystem" to gain a competitive advantage in the market. Finally, the possibility of patent alliances between $\mathrm{ND}$ and GX in the fields of cathode materials, anode materials, and electrode and diaphragm devices, as well as high standard technical barriers, also warrants BYD's attention.

BYD has a competitive advantage over ND and GX in the rechargeable battery field and will only need to maintain its current proportion of $\mathrm{R} \& \mathrm{D}$ investment in the rechargeable battery field to maintain its competitive advantage. In lithium iron phosphate materials, BYD's proportion of resource investment is far behind ND and GX, which indicates that BYD has considerable shortcomings in lithium iron phosphate materials. Based on the short-board effect of the "barrel principle," BYD is likely to limit the development of other related technologies because of the low proportion of resources invested in lithium iron phosphate material technology innovation point. In the future, BYD should increase its $R \& D$ investment in the lithium iron phosphate material field to actively catch up with its competitors and make up for shortcomings to ensure that the company's lithium iron phosphate material production technology and other lithium battery-related technologies can support the development. Based on the above analysis, BYD should classify GX and ND as its core technology competitors and use IPC number analysis to quickly understand GX and ND's macro technology development direction and patent layout. Through feature keyword analysis, the distribution of technology innovation points of GX and ND can be found timely, and resource allocation and patent bypass design can be adjusted timely.

\section{Conclusions and Recommendations}

This paper takes BYD company as an example, analyzes the macro technology development direction and micro technology innovation points of its competitors, and finally draws the following conclusions and recommendations. Firstly, IPC numbers shared by BYD and its competitors include H01M2 (structural parts or methods of manufacture of inactive components), H01M4 (electrodes), and H01M10 
(secondary batteries and their manufacture). The structural features or manufacturing methods of inactive ingredients and electrodes are the primary technical fields of lithium battery production and manufacturing. In contrast, the secondary battery is the frontier and hot technical field of the lithium battery industry. In the future, BYD company should continue to increase its investment in $R \& D$ and technology transfer in relevant areas to gain a competitive advantage in fundamental and hot technologies. Secondly, BYD should list GX and ND as core technology competitors.

On the one hand, BYD should keep an eye on the patent technology development direction of GX and ND, especially the competing trend between core technology and auxiliary technology, to be alert to competitors' patent layout $\mathrm{Li}$-ion battery technology.

On the other hand, BYD should continue to increase its $\mathrm{R} \& \mathrm{D}$ expenditure and $\mathrm{R} \& \mathrm{D}$ personnel in the technological innovation of cathode materials, anode materials, electrode plates, and separator devices to increase the number and quality of patents in these areas and actively counter the technological threat from GX and ND, and strive to gain a competitive advantage in the above-mentioned key technology areas of lithium batteries. Thirdly, YW's and HD's IPC technologies are more competitive and less similar in terms of technological innovation points, so BYD should pay more attention to the direction of its patent technology development and the technical correlation between patents of different IPC categories to prevent its patent layout in the future.

The similarity between GLM, TQ, and BYD's technology innovation points is high. Still, the competitive intensity of IPC technology is low, so BYD should pay more attention to its patent dynamics at a particular technology innovation point in the future to prevent patent infringement disputes or monopoly formation around a specific innovation of technology point. Fourthly, DS, TN, WL, and GF have lower competitive intensity of IPC technology and similarity of feature keywords with BYD company. Therefore, the above four companies pose a minor threat to BYD.

BYD can focus less on these four companies' patent developments and instead divert corporate resources to conducting patent intelligence analysis on other, more threatening competitors [21]. However, it should be noted that some of the competitors in these four companies, due to their strategic positioning and other reasons, invest a much higher proportion of their resources in individual technology innovation points, thus posing a greater technological threat to BYD company. For example, TN has a significant technological competitive advantage in the field of sealing components. Therefore, BYD company should also pay due attention to the patent dynamics and market share changes of such competitors in a particular technology innovation point to prevent them from forming a technology monopoly around a particular innovation point.

Lastly, BYD company can multiply its industry clusters' core competitiveness by setting up industrial patent alliances to gather the industry's core patents. Regarding the specific innovation, strong cooperation with alliance members is implemented by importing advanced lithium- ion battery technology from abroad, raising its overall technology level to the advanced international level. For example, it is recommended that cutting-edge technology (including slot die application technology and tension control technology) from Korea CIS is introduced to realize its lithium-ion batteries automation, intelligence, and digitalization electrode coating machine, which will fundamentally enhance the core competitiveness of the enterprise. The paper is limited to BYD, a leading company in China's lithium-ion battery industry, and ten competitors, and we will expand the scope and sample size in the future. Moreover, the empirical evidence's primary data in this paper is only from the Chinese patent database. The data of the patent sample can be extended to the patent information databases of the five principal global IP offices in the future.

Finally, the two-dimensional matrix model pioneered in this paper needs to be applied to more comparative analysis of core competencies among more firms in other technology sectors to better depict macro technology trends and micro technology innovation points and to help Chinese firms identify their core competitors on a global scale more precisely. This research suggests that the government should remove the hurdles, strengthen the overall network characteristics, and support and guide the core nodes within the lithium-ion power industry. It is also found in the study that the competition between enterprises in the industry is becoming increasingly fierce; quickly and efficiently identifying the core competitors has become the key to gaining a competitive advantage in the market.

4.1. Limitations and Suggestions. This study is based on the Chinese market. This study model can be applied in other countries or other markets around the globe. The scholars adopt this research for measuring more market clusters. This research was conducted through social networks and hierarchical cluster analysis, while researchers can add an extension to this study. The numbers of seminars can be increased for the sake of exchanges information regarding the collaborative experiments. It would increase the relationship on each other's innovative ideas, thoughts, and ways of conduct, to effectively enhance the innovative capacity of both partners to ensure the increase of cooperation intensity, i,e, collaboration of a series of economic activities implemented in a standard cooperation style between the innovation subjects of the lithium-ion power industry cooperation will be a complex but efficient innovation model. Furthermore, the guidance and supervision of the government are still indispensable in this process. The government needs to play an active role as a trigger to strengthen the awareness and conduct of each innovation body in reciprocal cooperation and adopt a more forward-looking legislative and regulatory mechanism to ensure the effective implementation of macro technology development cooperation. This paper conducts an empirical study using BYD as an example. It selects the top ten companies in the " 2016 China Lithium Battery Enterprises Comprehensive Strength Ranking," so it can get more companies for future research. 


\section{Data Availability}

The data used for this study are available and will be supplied upon request.

\section{Conflicts of Interest}

The authors declare no conflicts of interest.

\section{Authors' Contributions}

All the authors contributed equally to this work.

\section{Acknowledgments}

The authors acknowledge their financial supporters: Social Science Funding Project of Jiangsu Province (No. 18GLB024) and Key Research Base of Universities in Jiangsu Province for Philosophy and Social Science Research Center for Green Development and Environmental Governance.

\section{References}

[1] M. Shi, J. Luo, and L. Cai, "Research on identification of potential competitors based on semantic analysis of patent description," Journal of The China Society for Scientific and Technical Information, vol. 39, no. 11, pp. 1171-1181, 2020.

[2] P. Gautam and R. L. S. Olivia, "Web footprints of firms: using online isomorphism for competitor identification," Operations Research Management Science, vol. 57, pp. 117-120, 2017.

[3] S. Meng-Jung, L. Duen-Ren, and H. Ming-Li, "Discovering competitive intelligence by mining changes in patent trends," Expert Systems with Applications, vol. 37, no. 4, pp. 28822890, 2010.

[4] X. Ji, Y. L. Tsai, and A. Fleischhacker, "A uniqueness-driven similarity measure for automated competitor identification," International Journal of Applied Decision Sciences, vol. 12, no. 2, p. 179, 2019.

[5] Z. H. Song, L. Qi, and M. L. Dong, "Patent-based measurements on technological convergence and competitor identification: the case of semiconductor industry," European Journal of Business and Management, vol. 8, no. 30, pp. 40-45, 2016.

[6] M. Bergen and M. A. Peteraf, "Competitor identification and competitor analysis: a broad-based managerial approach," Managerial and Decision Economics, vol. 23, no. 4-5, pp. 157-169, 2002.

[7] G. Martin, "Moehrle. Measures for textual patent similarities: a guided way to select appropriate approaches," Scientometrics, vol. 85, no. 1, pp. 95-109, 2010.

[8] S. Taotao and L. Yun, "Competitive technical intelligence analysis for enterprises based on patents coupling," Science Research Management, vol. 9, 2011.

[9] Y. Wang and Y. Bao, "Research on patent competitiveness of hangzhou lithium battery industry statistical analysis based on innography software," Operation and Management, no. 10, pp. 69-73, 2014.

[10] E. Abad-Segura, A. Infante-Moro, M.-D. González-Zamar, and E. López-Meneses, "Blockchain technology for secure accounting management: research trends analysis," Mathematics, vol. 9, no. 14, Article ID 1631, 2021.
[11] J. Bayer and E. Servan-Schreiber, "Gaining competitive advantage through the analysis of customers' social networks," Journal of Direct, Data and Digital Marketing Practice, vol. 13, no. 2, pp. 106-118, 2011.

[12] Y. Hong and L. I. Ying-Min, "Visualization of technological similarity analysis for enterprises based on patent coupling approach," Studies in Science of Science, vol. 31, no. 7, pp. 1013-1021, 2013.

[13] C. Hu, M. Li, M. Zhang, M. Pan, and K. Guan, "Study on patent cooperation of Universities in shanghai based on social network analysis," Science and Technology Management Research, vol. 37, no. 14, pp. 119-127, 2017.

[14] J. Wang, L. Fuhai, and J. Tang, "A study on evaluating the future industry influence of emerging technologies," Journal of Intelligence, vol. 33, no. 8, pp. 70-75, 2014.

[15] W. Yu, W. Chen, and P. Ren, "Research on the social business strategy of the core business of Chinese enterprises," Social Science Front, no. 5, pp. 82-89, 2003.

[16] Li Huan and A. Peng, "Research of three patent citation analysis methods to identity, the competitors: an application to holography research," Journal of Intelligence, vol. 33, no. 10, pp. 78-82+71, 2014.

[17] M. Li, M. Zhang, M. Zhao, J. Zhao, and M. Zhang, "An empirical study on the relevance of patent transactions and patent litigation," Social Sciences in Xinjiang, no. 1, pp. 27-32, 2017.

[18] Q. Long, X. Wu, and R. Na, "Competitors analysis and empirical research based on social network analysis," Information Science, vol. 31, no. 1, pp. 134-141+160, 2013.

[19] M. Li, M. Zhang, C. Hu, J. Su, and M. Zhang, "Innovation research on operation model of patent pool concerning intellectual property intensive industry," Science and Technology Progress and Policy, vol. 33, no. 22, pp. 64-68, 2016.

[20] Y. Zhao and J. Li, "Current and development trends of Chinese patents in lithium battery," Journal of Intelligence, vol. 31, no. 1, pp. 35-40+16, 2012.

[21] Z. Li, "A summary of similarity measure functions commonly used in cluster Analysis," Digital Technology and Application, no. 11, p. 233, 2016. 